\title{
Azotla Gübrelemenin Kırmızı Biber Bitkisinin Tepe ve Kök Gelişimi İle Bazı Bitki Besin Maddesi İçerikleri Üzerine Etkisi
}

\author{
Yaşar KASAP1, Bülent TOPCUOĞLU², \\ Geliş Tarihi : 10.04.1996
}

S.Rıfat YALÇIN ${ }^{2}$

\begin{abstract}
Özet: Kırmızı toz biberi uretiminde kullanılan Kahramanmaraş kırmızı biber çeşidi serada azotlu gübreleme ile denemeye alınmıştır.

Toprağa artan miktarlarda uygulanan azotlu gübre 25 ve 50 ppm N duzeylerinde bitkinin tepe ve kök ürün miktarını ve $\mathrm{P}, \mathrm{K}, \mathrm{Ca}, \mathrm{Mg}, \mathrm{Fe}, \mathrm{Cu}, \mathrm{Zn}$ ve Mn içeriklerini artırırken 100 ve 150 ppm N düzeylerinde anılan bu parametreler azalma eğilimi göstermiştir. Azot içeriği azotlu gübrenin artan miktarlardaki uygulamaları ile ilgili olarak surekli artmıştır.
\end{abstract}

Anahtar Kelimeler: Kırmızı biber, azotlu gübreleme, vejetatif üün, bitki besin içerikleri

\section{Effect of Nitrogen Fertilization on the Growth of Top and Root and Some Plant Nutrient Contents of Red Pepper Plant}

\begin{abstract}
Kahramanmaraş red ppper variety which is used in milled red pepper production was examined with nitrogen fertilization in greenhouse.

Nitrogenous fertilizer which is applied to soil in increasing amounts, increased top and root yields and $\mathrm{P}, \mathrm{K}, \mathrm{Ca}, \mathrm{Mg}$, $\mathrm{Fe}, \mathrm{Cu}, \mathrm{Zn}$ and $\mathrm{Mn}$ contents in 25 or 50 ppm N levels, while 100 or $150 \mathrm{ppm} \mathrm{N}$ levels decreased this mentioned parameters, Nitrogen content is increased by the application of increasing amounts of nitrogen fertilizer.
\end{abstract}

Key Words: Red pepper, nitrogenous fertilization, vegetative yield, plant nutrient contents.

\section{Giriş}

Dünyada ve ülkemizde ticari olarak 5 tip biber cinsinin kültürü yapılmaktadır. Bu biber cinslerinin hepsi toz biber üretimine uygun olmamaktadır. Ülkemizde Kahramanmaraş, Şanlıurfa, Kayseri, Bursa ve Bilecik yörelerinde yetiştirilen biber cinsleri kırmızı toz biber üretimine elverişli olup, Bilecik ve Bursa yörelerinde yetiştirilen biber cinsleri tatlı, Kahramanmaraş, Şanlıurfa ve Gaziantep yörelerinde yetiştirilen biber cinsleri ise acı cinsindendir.

Kahramanmaraş kırmızı biberi ticari kapasite bakımından ülkemizde yetişen en iyi biber çeşididir. Kahramanmaraş kırmızı biberi ülkemiz iç pazarı için gerekli olduğu kadar Ortadoğu ülkelerine olan dışsatım potansiyeliylede önemli bir ekonomik büyüklüğu sahiptir.

Bu çalışmada Kahramanmaraş yöresinde geniş bir üretim sahasında tarımı yapılan Kahramanmaraş kırmızı biberinin üretiminde bitkinin beslenme sorunlarını aydınlatıcı bazı verilerin elde edilmesi amaçlanmıştır. Bu amaçla serada yapılacak çalışmada toprağa değişik miktarlarda uygulanan azotlu gübrenin Kahramanmaraş kırmızı biber çeşidinin tepe ve kök ürün miktarı ile bazı bitki besin maddesi içerikleri üzerine etkileri incelenmiştir.

\section{Materyal ve Yöntem}

Bu araştırmada kullanılan toprak örneği Kahramanmaraş iline bağlı Merkez köyünden, biber yetiştirilen bir tarladan alınmıştır. Alüviyal büyük toprak grubundan olan toprak örneği $0-20 \mathrm{~cm}$ den alınmış ve Jackson (1962) tarafından bildirilen ilkelere uygun olarak denemeye hazırlanmıştır. Deneme toprağının bazı fiziksel ve kimyasal özellikleri Çizelge 1'de verilmiştir.

Serada yapılan denemede Kahramanmaraş yöresinde yetiştirilen ve Kahramanmaraş biberi olarak bilinen kırmızı biber çeşidi tesadüf parselleri deneme desenine göre üç tekerrürlü olarak $4 \mathrm{~kg}$ mutlak kuru toprakialan plastik saksılarda yetiştirilmiştir.

Deneme saksılarına azotlu gübre (amonyum sülfat) aşağıdaki düzeylerde uygulanmıştır.

$$
\begin{aligned}
& \text { N0 }=0 \text { ppm N (Kontrol) } \\
& \text { N1 }=25 \mathrm{ppm} \mathrm{N} \\
& \text { N2 }=50 \mathrm{ppm} \mathrm{N} \\
& \mathrm{N} 3=100 \mathrm{ppm} \mathrm{N} \\
& \mathrm{N} 4=150 \mathrm{ppm} \mathrm{N}
\end{aligned}
$$

Ayrıca her saksıya $50 \mathrm{ppm}$ fosfor (triple süperfosfat) ve $50 \mathrm{ppm}$ potasyum (potasyum sülfat) temel gübre olarak verilmiştir. Tüm gübreleme işlemleri çözelti şeklinde uygulanmış ve toprakla iyice karıştırılmıştır.

Biber tohumları saf perlit ortamında çimlendirildikten 9 gün sonra, fideleri saksılardaki toprağa şaşırtılmıştır. Fideler toprağa şaşıtıldıktan 30 gün sonra Geraldson ve

\footnotetext{
1 Kahramanmaraş Sütçü Imam Üniv Ziraat Fak. Toprak Bölümü - Ankara

2 Ankara Üniv. Ziraat Fak. Toprak Bölümü - Ankara
} 
Tylor (1990) tarafından, bildirildiği şekilde biber bitkilerinin gelişimini tamamlamış genç yapraklarından analizler için yaprak örnekleri alınmış ve analize hazırlanmıştır. Tüm bitkiler toprağa şaşırtıldıktan 45 gün sonra tepe aksamı toprak yüzeyinden kesilerek ve kök aksamı suyla ayrılıp temizlenerek hasat edilmiş ve kurutma dolabında $65{ }^{\circ} \mathrm{C}$ de kurutulmuştur.

Hasattan önce alınan yaprak örneklerinde toplam azot Bremner (1965), toplam fosfor, potasyum, kalsiyum, magnezyum Kacar (1972), demir, bakır, çinko ve mangan ise Anonymous (1973) tarafından bildirildiği şekilde belirlenmiştir.

Araştırma bulgularının varyans analizleri Minitab programında, ortalamalar arasındaki farklılığın önemlilik derecesi ise Mstat programında LSD testi yapılarak belirlenmiştir.

\section{Bulgular ve Tartışma}

Toprağa değişik miktarlarda uygulanan azotlu gübrenin Kahramanmaraş kırmızı biber çeşidinde tepe ve kök ürün miktarı ile azot, fosfor, potasyum, kalsiyum, magnezyum, demir, bakır, çinko ve mangan içerikleri üzerine etkileri ve istatistiki analizleri toplu olarak Çizelge 2'de gösterilmiştir.

Toprağa değişik miktarlarda uygulanan azotlu gübre biber bitkisinin tepe ve kök ürün miktarı ile azot, fosfor, potasyum, kalsiyum, magnezyum, demir, bakır içerikleri üzerine istatistiki yönden \% 1 düzeyinde, çinko ve mangan içerikleri üzerine ise $\% 5$ düzeyinde önemli etki yapmıştır. Biber bitkisinin tepe ve kök ürün miktarı, tepe/kök oranı ve toplam azot dışında incelenen bitki besin maddesi içerikleri azotlu gübre uygulamalarının N2 düzeyinde ( 50 ppm N) en yüksek elde edilmiştir.

Toprağa artan miktarlarda uygulanan azotlu gübre ile ilgili olarak biber bitkisinin tepe ve kök ürün miktarı azot uygulamlarının N2 düzeyine kadar sürekli artmış, N3 ve N4 düzeylerinde azalarak kontrolden daha düşük elde edilmiştir. Toprağa artan miktarlarda uygulanan azotlu gübre ile ilgili olarak Knavel (1977) ve Kulvinder ve ark. (1988) biber bitkisinin tepe ve kök gelişminin arttığını, Vlcek ve Polach (1976) biber bitkisinde en yüksek tepe ürün miktarının toprağa 80 ppm N uygulamasınida elde

Çizelge 1. Deneme toprağının bazı fiziksel ve kimyasal özellikleri.

\begin{tabular}{|c|c|c|}
\hline \multicolumn{2}{|c|}{ Özellikler } & \multirow[t]{2}{*}{ Yöntemler } \\
\hline Tekstür & Kumlu Killi Tın & \\
\hline Kum, \% & 53.84 & \\
\hline Kil, \% & 23.44 & \\
\hline Silt, \% & 22.72 & \\
\hline $\mathrm{pH}$ & 7.20 & Grewelling ve Peech (1960) \\
\hline Organik Madde, \% & 2.11 & Jackson (1962) \\
\hline Bitkiye Yarayıșlı Fosfor, ppm & 6.78 & Olsen ve ark. (1954) \\
\hline Deg.Potasyum, me $/ 100 \mathrm{~g}$ toprak & 1.43 & Prat (1965) \\
\hline Değ. Kalsiyum, me/100 g toprak & 14.83 & Prat (1965) \\
\hline Değ. Magnezyum, me $/ 100 \mathrm{~g}$ toprak & 4.57 & Prat (1965) \\
\hline Bitkiye Yarayıș/ı Demir, ppm & 8.92 & Lindsay ve Norwell (1978) \\
\hline Bitkiye Yarayışlı Mangan, ppm & 6.44 & Lindsay ve Norwell (1978) \\
\hline Bitkiye Yarayışı Cinko, ppm & 1.96 & Lindsay ve Norwell (1978) \\
\hline Bitkiye Yarayıșlı Bakır, ppm & 0.81 & Lindsay ve Norwell (1978) \\
\hline
\end{tabular}

Çizelge 2. Toprağa değişik miktarlarda uygulanan azotlu gübrenin Kahramanmaraş kırmızı biber çeşidinde N, P, K, $\mathrm{Ca}, \mathrm{Mg}, \mathrm{Fe}, \mathrm{Cu}, \mathrm{Zn}$ ve $\mathrm{Mn}$ içerikleri uzerine etkisi.

\begin{tabular}{|c|c|c|c|c|c|c|c|c|}
\hline & \multicolumn{5}{|c|}{ AZOT UYGUL AM AL ARI } & \multirow[b]{2}{*}{ LS D } & \multirow[b]{2}{*}{ Kareler Ort. } & \\
\hline & No & N1 & N2 & N3 & N4 & & & \\
\hline TEPE, g/saksı & $16.88^{\mathrm{C}} \mathrm{c}$ & $19.25 \mathrm{~b}$ & $25.39 a$ & $10.28 \mathrm{~d}$ & $3.95 \mathrm{e}$ & $0.695^{y}$ & 205.390 & k* \\
\hline KOK, g/saksı & $10.77 \mathrm{c}$ & $12.46 \mathrm{~b}$ & $16.02 \mathrm{a}$ & $7.98 \mathrm{~d}$ & $3.06 \mathrm{e}$ & 0.415 & 71.370 & ** \\
\hline TEPE/KOK oranI & $1.57 \mathrm{a}$ & $1.55 \mathrm{a}$ & $1.58 \mathrm{a}$ & $1.29 \mathrm{~b}$ & $1.29 \mathrm{~b}$ & 0.077 & 0.071 & \#* \\
\hline AZOT, $\%$ & $2.98 \mathrm{e}$ & $3.10 \mathrm{~d}$ & $4.15 \mathrm{c}$ & $5.36 \mathrm{~b}$ & $6.01 \mathrm{a}$ & 0.218 & 7.430 & \# \\
\hline FOSFOR, \% & $0.31 \mathrm{~d}$ & $0.40 \mathrm{~b}$ & $0.47 \mathrm{a}$ & $0.36 \mathrm{c}$ & $0.29 \mathrm{~d}$ & 0.036 & 0.016 & ** \\
\hline POTASYUM, $\%$ & $3.21 \mathrm{c}$ & $3.62 \mathrm{~b}$ & $4.26 \mathrm{a}$ & $2.92 d$ & $2.63 \mathrm{e}$ & 0.173 & 1.215 & \#* \\
\hline KALSIYUM, \% & $3.58 \mathrm{c}$ & $4.06 \mathrm{~b}$ & $4.50 \mathrm{a}$ & $3.05 \mathrm{~d}$ & $2.92 \mathrm{~d}$ & 0.180 & 1.336 & ** \\
\hline MAGNEZYUM, $\%$ & $1.31 \mathrm{c}$ & $1.73 \mathrm{~b}$ & $2.18 \mathrm{a}$ & $1.18 \mathrm{~cd}$ & $1.09 \mathrm{~d}$ & 0.167 & 0.616 & ** \\
\hline DEMIR, ppm & $194 \mathrm{~b}$ & $212 \mathrm{~b}$ & $240 a$ & $199 \mathrm{~b}$ & $151 \mathrm{c}$ & 17.390 & 3086.620 & \#* \\
\hline BAKIR, ppm & $13 \mathrm{c}$ & $19 b$ & $26 a$ & $11 \mathrm{c}$ & $9 c$ & 3.285 & 143.000 & ** \\
\hline ÇINKO, ppm & $43 c$ & $51 \mathrm{~b}$ & $65 a$ & $50 \mathrm{~b}$ & $48 \mathrm{bc}$ & 6.169 & 201.900 & * \\
\hline MANGAN, ppm & $53 c$ & $69 b$ & $88 a$ & $48 \mathrm{c}$ & $39 d$ & 7.654 & 1096.200 & 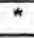 \\
\hline
\end{tabular}

x: Değerler 3 tekerrürán ortalamasıdır, $y$ : Karşılaştırmalarda \% 5 önem düzeyi kullanılmıştır. ${ }^{* *}$; $P<0.01 \quad$ *; $P<0.05$ 
olunduğunu, Sriniva ve Prabhakar (1982) ise biber bitkisinin tepe ve kök urün miktarlarının uygulanan azotla ilgili olarak arttığını ancak yüksek azot uygulamlarında tepe ve kök ürün miktarlarının azaldığını belirlemişlerdir.

Blber bitkisinin $N$ içeriği toprağa artan miktarlarda uygulanan azotlu gübre ile ilgili olarak sürekli artarken, $P$. $\mathrm{K}, \mathrm{Ca}, \mathrm{Mg}, \mathrm{Fe}, \mathrm{Cu}_{1} \mathrm{Zn}$ ve $\mathrm{Mn}$ içerikleri azot uygulamalarinin N2 düzeyine kadar artmiş N3 ve N4 düzeylerinde azalmıştır.

Pandev ve ark (1987) toprağa verilen azotun biber bitkisinde $\mathrm{N}, \mathrm{P}, \mathrm{K}, \mathrm{Ca}$ ve $\mathrm{Mg}$ alımını olumlu etkilediğini bildirmişlerdir. Knavel (1977) biber bitkisi yapraklarında $P$ içeriğinin azoțu gübre uygulamaları ile ilgili olarak arttığını, biber bitkisi yaprağında en uygun azot düzeyinin yaklaşık olarak kuru maddede $\% 3.7$ olduğunu bildirmiştir.

Yüksek azot uygulamlarında $P$ ve $\mathrm{Ca}$ içeriklerinin azalmasina ilişkin Ehrendorfer (1964). Haddock ve ark. (1957), Çağatay ve ark (1968) değişik bitkilerde benzer sonuçlar elde etmişlerdir. Biber bitkisinde yüksek azot düzeylerinde $\mathrm{Cu}$ içeriğinin azalmasına ilişkin Fleming ve delanay (1961), Thiel ve Finc (1973), Robson ve Reuter (1981) tarafından bildirildiği şekilde fazla miktarlardaki azotun $\mathrm{Cu}$ alımina olumsuz etki yapması. Hill ve ark. (1978) tarafından bildirildiği şekilde azotun bakır yarayışlılığı ve mobilitesi üzerine etki yapmasından kaynaklanmaktadir. Yüksek azotlu gübre uygulamalarında $\mathrm{Zn}$ ve $\mathrm{Mn}$ içeriklerinin azalmasına ilişkin Camp (1945), Ozanne (1955), Turan ve Yürür (1978) tarafından benzer bulgular saptanmıştır

\section{Sonuç}

Toprağa artan miktarlarda uygulanan azotlu gübrenin $50 \mathrm{ppm}$ düzeyine kadar biber bitkisinin tepe ve kök ürün miktarını, $\mathrm{P}, \mathrm{K}, \mathrm{Ca}, \mathrm{Mg}, \mathrm{Fe}, \mathrm{Cu}_{1} \mathrm{Zn}$ ve $\mathrm{Mn}$ içeriklerini arttırdığı, N3 ve N4 düzeylerinde tepe ve kök ürün miktarı lle azot dışındaki bitki besin içeriklerini azaltığı saptanmıştır. Mevcut bulgular ve literatür bildirişleri göz önune alındığında biber bitkisine uygulanan $50 \mathrm{ppm}$ civarındaki azotun ürün miktarı ve bitki besin içeriği ûzerine olumlu etki yaptığı görülmektedir. Bu nedenle kırmızı biber bitkisinin gübrelenmesinde yüksek azotlu gübre uygulamlanndan kaçınmak yüksek bir tepe ve kök ürün miktarı ile bitkide uygun bir besin maddesi dengesini sağlamak yönünden önem taşımaktadır.

\section{Kaynakiar}

Anonymous, 1973. Analytical methods for atomic absorption spectrofotometry. Perkin elmer Catolog, Norwalk. Conneccticut USA.

Bouyoucos, G.D. 1951. A recalibration of hydrometer method for making mechanical analysis of the soil Agronomy Jour., 43, 434-438

Bremner, J.M. 1965. Methods of soil analysis, Part 2, Chemical and microbiological properties. Ed. C.A. Black, Amer. Soc. of Agron. Inc. Pub Agron. Series No. 9

Camp, A.F. 1945. Zinc as a nutrient in plant growth. Soil Sci, $60,157-164$
Çağatay, M. B. Kacar ve C. Turan, 1968. Değişik miktarlarda toprağa verilen azotlu gubbrenin misır bitkisinin fosfordan faydalanması üzerine tesirleri. A.U. Ziraat Fakultesi Yayınları, 349, Bilimsel araştıma ve incelemeler, 222, Ankara

Ehrendorfer K 1964. Einfluss der Mineralstaffgehalte, insbesonder der phosphorgehaltes auf den oxalsaure gehalt von spinat (spinaceae oleraceae L.). Die Phosphorsaure, 24, 180-198.

Fleming, G.A, and J. Delaney, J. 1961. Copper and nitrogen in the nutrition of wheat on cutaway peat. Ir. Jour. Agr. Res. $1,81-84$

Geraldson, C.M. K.B. Tylor. 1990. Soil testing and Plant analysis. SSSA Book series: 3 inc, Madison, Wisconsin, USA.

Grewelling, T. and M. Peech, 1960, Chemical Soil Tests. Cornell Uni. Agr. Expt. Station. Bull. 960.

Haddock J K, B.R.L Hausen and C.D. Stanberg, 1957 Studies with radioactive phoshphorus in soil of the western states. 1950-1953. United States Department of Agricultures Production Research Report, No. 12, pp 32.

Hill, J., A.D Robson and J.F. Loneragan, 1978. The effect of copper and nitrogen supply on the retranslocation of copper in four cultivars of wheat. Aust. J. Agric. Res., 29, 925-939.

Jackson, M.L, 1962. Soil chemical analysis. Prentice-Hall Inc. Eng. Cliffers, U.S,A

Kacar, B. 1972. Bitki ve Toprağın Kimyasal Analizleri, II. Bitki analizleri, A.Ü. Zlraat Fak. Yayınları:453, Uygulama Klavuzu:155, A.Ü. Basımevi, Ankara.

Knavel, D.E, 1977. The influences of nitrogen on pepper transplant growth and yielding potential of plants grown with different levels of soil nitrogens. Journal of the Amer. Soc. for Horticultural Science. 102 (5), 533-535

Kulvinder, S, B.K. Srivastava, K, Singh. 1988 Effects of various levels of nitrogen and phosphorus on growth and yield of chilli (Capsicum annum L.) Indian Journal of Horticulture. 45 (3-4), 319-324.

Lindsay, W.L. ve W.A. Norwell, 1978, Development of DPTA Soil Tests for Zinc, Iron, Manganese and Copper. Soil Sci. Soc. Amer Proc, $42(3): 421-428$

Ozanne, $P G, 1955$. The effect of nitrogen on zinc deficiency in subterranen clover. Aus. Jour, Biol Sci., 8, 47-55

Olsen, S.R., C.V. Cole, F.S. Watanabe and H.C. Dean, 1954. Estimation of available phosphorus in soil by exaction with sodium bicarbonate. U.S. Dept. of Agr. Cir. 939. Washington $D, C$.

Pandev, S., L.Milkova, T., Kdrev, 1987. Effect of mineral nutrition on the yield and quality of capsicum cultuvars and hybrid combinations. Fiziologiyana Rasteniyata 13:3, 50-58.

Pratt, P.F. 1965. Methods of soil analysis, Part 2, Chemical and microbiological properties. Ed. C.A. Black, Amer, Soc. of Agron. Inc. Pub. Agron Series. No. 9. Madison, Wisconsin, U.S.A.

Robson, A.D. and D.J. Reuter, 1981. Diagnosis of copper deficiency and toxicity."In Copper in soils and plants" (J.F. Loneragan, A.D. Robson and R.D. Graham, eds.) 287-312. Academic Press, London.

Sriniva, K. B.S., Prabhakar 1982. Response of capsicum to nitrogen fertilization. Vegetable Science. 9:2, 71-74

Thiel, $H$. and A. Finck, 1973. Ermittlung von Grenzwerten optimaler Kupfer-Versorgung für $\mathrm{Hafer}$ and Sommergerste. Z. Pflanzenernahr. Bodenk., 134, 107-125.

Turan, C., B. Yürür, 1978. Misir bitkisi kökünün mikroelement kapsamları üzerine artan miktarlardaki azotlu gübrelerín etkileri. Ankara Üniversitesi Ziraat Fakültesi Yıllığı, Cilt 28 , Fasikul 3-4, Ankara Üniversitesi Basimevi, Ankara.

Vlcek, F., Polach, J. 1977. Fertilization and irrigation of greenhouse paprika. Soil and Fertilizer Abstracts, Vol. 40 , No. 5, Abstract No. 2743 